\title{
Profile of Interdialytic Blood Pressure in Hemodialysis Patients
}

\author{
Sergio F.F. Santos ${ }^{a}$ Roger B. Mendes ${ }^{a, b}$ Carlos A. Santos ${ }^{a}$ David Dorigo ${ }^{a}$ \\ Aldo J . Peixoto ${ }^{c}$ \\ aDivision of Nephrology, State University of Rio de J aneiro, Rio de J aneiro, RJ , and b Grupo de Assistência Médica e \\ Nefrológica (GAMEN), Rio de J aneiro, RJ , Brazil; cSection of Nephrology, Yale University School of Medicine, \\ New Haven, Conn., and Renal Section, VA Connecticut - West Haven Campus, West Haven, Conn., USA
}

\section{Key Words}

Ambulatory blood pressure monitoring - Chronic kidney failure - Circadian rhythm $\cdot$ Hemodialysis $\cdot$ Hypertension

\begin{abstract}
Background and Methods: Hypertension is a common problem in hemodialysis (HD). However, its behavior during the interdialytic period is not completely known and is infrequently monitored in clinical practice. Thus, for better understanding of interdialytic blood pressure (BP), we analyzed the interdialytic blood pressure profile using 44-hour ambulatory blood pressure monitoring (ABPM) data in 71 unselected, stable HD patients. Results: There was an increase in BP during the interdialytic period (awake day 1: 135/84 \pm 23/14 $\mathrm{mm} \mathrm{Hg}$; awake day 2: 140/86 \pm 22/15 mm Hg, $\mathrm{p}<0.05$; sleep day $1:$ 130/77 \pm 24/15 mm Hg; sleep day 2: 136/80 $\pm 24 / 15 \mathrm{~mm} \mathrm{Hg}, \mathrm{p}<$ 0.05). The correlation between the average 44-hour BP
\end{abstract}

Some of the subjects included in this paper $(n=8)$ were part of a previous publication [Peixoto et al: Am J Kidney Dis 2000;36:983990]. and interdialytic weight gain (IDWG) was not significant ( $r=-0.07$ for systolic BP and $r=-0.09$ for diastolic BP). The number of non-dipper patients was high, $77 \%$ on interdialytic day 1 and $83 \%$ on interdialytic day 2 for systolic BP. Uncontrolled hypertension (average $44 \mathrm{~h}$ BP $\geq 135 / 85 \mathrm{~mm} \mathrm{Hg}$ ) was diagnosed in $58(55 \%)$ patients. Patients with uncontrolled hypertension had higher preand posthemodialysis BP, higher BP on each interdialytic day and night, and higher night/day diastolic BP ratio on the second interdialytic day. These patients were also taking a greater number of vasoactive medications ( 1.5 vs. 0.6 in those with controlled BP, $p=0.001$ ). There were no significant differences related to $\mathrm{kt} / \mathrm{N}$, hematocrit, or weekly erythropoietin dose between patients with controlled or uncontrolled BP. Hemodialysis shift assignment (morning or afternoon) did not impact on BP levels or diurnal profile. Conclusion: In HD patients, interdialytic BP is often poorly controlled, there is a progressive rise in BP, and a trend toward loss of nocturnal decline in BP as the interdialytic period progresses. Further research is needed to determine whether treatment directed to interdialytic BP changes can alter outcomes in HD patients.

Copyright @ 2003 S. Karger AG, Base

\section{KARGER}

Fax + 41613061234 E-Mail karger@karger.ch www. karger.com (c) 2003 S. Karger AG, Base

0250-8095/03/0232-0096\$19.50/0

Accessible online at:

www. karger.com/ajn
Aldo J Peixoto, MD

Renal Section - 111F, West Haven VA Medical Center

950 Campbell Ave. West Haven, CT 06510 (USA)

Tel. +1 203932 5711, ext 3950, Fax +1 2309373455

E-Mail aldo.peixoto@yale.edu 


\section{Introduction}

Hypertension is a common problem in patients with end-stage renal disease on hemodialysis [1]. In this population, the observation of large variations of blood pressure (BP) during each hemodialysis (HD) and the fluctuation of BP levels in the interdialytic period suggest that more frequent interdialytic blood pressure measurement may be necessary to obtain a reliable blood pressure profile, and interdialytic ambulatory blood pressure monitoring (ABPM) may be the best method to evaluate the blood pressure profile in this group of patients [2,3]. Besides providing a larger number of readings and information throughout the interdialytic period, ABPM also has the unique property to evaluate blood pressure during sleep, which may be relevant data to be added to the patient's cardiovascular risk profile $[4,5]$.

Many studies have been published addressing the value of ABPM in end-stage renal disease [summarized in references 6-11]. However, most studies involve relatively small numbers of patients and limited uniformity in data collection and analysis. Thus, significant gaps exist in the understanding of the impact of clinical factors on the behavior of BP in the interdialytic period, and an evaluation of the prevalence of blood pressure control according to observed interdialytic readings. Accordingly, we present herein the analysis of a large population of hemodialysis patients studied with interdialytic BP monitoring in an attempt to understand BP behavior and the implications thereof on patient evaluation and management.

\section{Methods}

\section{Subjects and Clinical Data}

Patients who were stable on chronic hemodialysis for at least 3 months were eligible for the study and were invited to participate. Out of 160 patients, 90 were invited to participate after screening for exclusion criteria, and 71 subjects completed the study procedures and were included in this report. The following exclusion criteria were taken into account in patient recruitment: inability to provide informed consent, failure to complete a successful ambulatory blood pressure monitoring study as described below, unstable congestive heart failure or coronary artery disease, and atrial fibrillation. Data on many of the subjects included in this report have been reported in part in other publications [3].

All patients were receiving thrice weekly hemodialysis with volumetric dialysis machines using bicarbonate-based dialysate, and polysulfone dialyzers. Demographic and clinical data were obtained from patients' records. Estimated dry weight (EDW) was determined through standard clinical criteria. Ultrafiltration (UF) and interdialytic weight gain (IDWG) were determined based on changes in body weight before and after the index hemodialysis (UF), or between the end of the index hemodialysis and return to the next session (IDWG). In order to allow for better interpretation of clinical indices, we corrected the UF to pre-hemodialysis weight, and the IDWG to the estimated dry weight, thus obtaining measures that were more relevant to each specific patient. Data were collected regarding use of antihypertensive drugs (type, dose and schedule), as well as kt/V urea, hematocrit, and erythropoietin use and dose at the time closest to the index ABPM (within 3 weeks).

\section{Blood Pressure Measurement}

Blood pressure was measured at the dialysis unit as well as during the interdialytic period. Pre- and posthemodialysis BP were measured by the dialysis nurses, in the seated position, using a mercury sphygmomanometer. Auscultatory measurements followed standard clinical guidelines [12] using Korotkoff I and V sounds to indicate systolic and diastolic BP, respectively.

Interdialytic BP was measured throughout a midweek interdialytic period using an ambulatory BP monitor (Spacelabs 90207, SpaceLabs Medical, Redmond, Va., USA, a validated instrument $[13,14])$. Instrument hook-up and calibration followed standard protocols [15]. Monitoring was initiated immediately following HD and concluded immediately before the following HD, approximately $44 \mathrm{~h}$ later. Readings were obtained every $30 \mathrm{~min}$ throughout the monitoring period. In order to be accepted as a valid study we required at least $36 \mathrm{~h}$ of monitoring with at least one valid reading per hour. Awake and sleep periods were determined based on patient diaries.

Ambulatory BP variables included average interdialytic systolic BP (SBP), diastolic BP (DBP), pulse pressure (PP), average awake and sleep BP for each interdialytic day, and the day-night BP changes on each interdialytic day. We considered patients to have uncontrolled HTN if their average interdialytic BP was $135 / 85 \mathrm{~mm} \mathrm{Hg}$ or greater. For this analysis, we also expressed the relationship between awake and sleep BP in two different ways: the night:day ratio (sleep $\mathrm{BP} /$ awake BP), a continuous, more precise variable, and the arbitrary definition of 'dipper' (BP fall $\geq 10 \%$ during sleep, i.e. night:day ratio $\leq 0.90$ ) or 'non-dipper' (BP fall $<10 \%$, i.e. night:day ratio $>0.90$ ). Patients were told to take their medications in their usual schedule during the period of monitoring.

\section{Statistical Analysis}

Data are presented as mean \pm SD. We used paired and unpaired Student's t test to compare continuous variables and the chi-squared test to compare categorical variables. Pearson correlation coefficients and simple linear regression were used to study the relationship between different continuous variables. We used the statistical package Statistica version 5.1 (StatSoft, Inc., Tulsa, Okla., USA) for all calculations.

\section{Results}

Seventy-one patients ( 36 male, 35 female) with a mean age of $45 \pm 14$ years were included in the study. Median time since initiation of hemodialysis was 17 months (range 3-153 months). Hypertension was the presumed cause of the end-stage renal disease in 44 patients $(62 \%)$, 
Table 1. Ambulatory blood pressure values $(\mathrm{mm} \mathrm{Hg})$ in 71 stable hemodialysis patients $($ mean $\pm \mathrm{SD})$
Table 2. Concordance in the definition of uncontrolled hypertension between casual peri-dialysis BP values and ambulatory interdialytic BP

\begin{tabular}{lccc}
\hline & $\begin{array}{l}\text { Systolic } \\
\text { BP }\end{array}$ & $\begin{array}{l}\text { Diastolic } \\
\text { BP }\end{array}$ & $\begin{array}{l}\text { Pulse } \\
\text { pressure }\end{array}$ \\
\hline Pre-HD & $151 \pm 28$ & $83 \pm 15$ & $67 \pm 20$ \\
Post-HD & $143 \pm 26$ & $81 \pm 15$ & $63 \pm 17$ \\
48 average & $136 \pm 22$ & $83 \pm 14$ & $52 \pm 14$ \\
Awake day 1 & $135 \pm 23$ & $84 \pm 14$ & $50 \pm 13$ \\
Awak e day 2 & $140 \pm 22^{* * *}$ & $86 \pm 15^{*}$ & $55 \pm 15^{*}$ \\
Awake BP difference (day 2 - day 1) & $5.3 \pm 9.0$ & $1.2 \pm 6.1$ & $3.8 \pm 6.6$ \\
Sleep day 1 & $129 \pm 24$ & $77 \pm 15$ & $52 \pm 14$ \\
Sleep day 2 & $136 \pm 24^{* * *}$ & $80 \pm 15^{* *}$ & $56 \pm 16^{*}$ \\
Sleep BP difference (day 2 - day 1) & $6.5 \pm 11.5$ & $2.3 \pm 7.4$ & $4.1 \pm 6.5$ \\
Night/day ratio day 1 & $0.95 \pm 0.10$ & $0.92 \pm 0.09$ & N/A \\
Night/day ratio day 2 & $0.97 \pm 0.0 .08$ & $0.93 \pm 0.09$ & N/A \\
Night/day ratio difference (day 2 - day 1) & $0.017 \pm 0.094$ & $0.016 \pm 0.094$ & N/A \\
Dipper/non-dipper day 1 & $16 / 55$ & $35 / 36$ & N/A \\
Dipper/non-dipper day 2 & $12 / 59$ & $29 / 42$ & N/A \\
& & & \\
\hline
\end{tabular}

HD = Hemodialysis; Dip = dipper; Non-dip = non dipper; N/A= not applicable.

$* \mathrm{p}<0.05$ vs. interdialytic day $1 .{ }^{* *} \mathrm{p}<0.01$ vs. interdialytic day $1 .{ }^{* * *} \mathrm{p}<0.001 \mathrm{vs}$. interdialytic day 1 .

\begin{tabular}{|c|c|c|c|c|}
\hline & $\begin{array}{l}\text { ASBP } \\
\geq 135 \mathrm{~mm} \mathrm{Hg}\end{array}$ & $\begin{array}{l}\text { ASBP } \\
<135 \mathrm{~mm} \mathrm{Hg}\end{array}$ & $\begin{array}{l}\text { ADBP } \\
\geq 85 \mathrm{~mm} \mathrm{Hg}\end{array}$ & $\begin{array}{l}\text { ADBP } \\
<85 \mathrm{~mm} \mathrm{Hg}\end{array}$ \\
\hline \multicolumn{5}{|l|}{ Pre-HD SBP } \\
\hline$\geq 140 \mathrm{~mm} \mathrm{Hg}(\mathrm{n}=47)$ & 27 & 20 & - & - \\
\hline$<140 \mathrm{~mm} \mathrm{Hg}(\mathrm{n}=24)$ & 5 & 19 & - & - \\
\hline \multicolumn{5}{|l|}{ Pre-HD DBP } \\
\hline$\geq 90 \mathrm{~mm} \mathrm{Hg}(\mathrm{n}=25)$ & - & - & 17 & 8 \\
\hline$<90 \mathrm{~mm} \mathrm{Hg}(\mathrm{n}=46)$ & - & - & 11 & 35 \\
\hline \multicolumn{5}{|l|}{ Post-HD SBP } \\
\hline$\geq 140 \mathrm{~mm} \mathrm{Hg}(\mathrm{n}=41)$ & 26 & 15 & - & - \\
\hline$<140 \mathrm{~mm} \mathrm{Hg}(\mathrm{n}=30)$ & 6 & 24 & - & - \\
\hline \multicolumn{5}{|l|}{ Post-HD DBP } \\
\hline$\geq 90 \mathrm{~mm} \mathrm{Hg}(\mathrm{n}=23)$ & - & - & 19 & 4 \\
\hline$<90 \mathrm{~mm} \mathrm{Hg}(\mathrm{n}=48)$ & - & - & 9 & 39 \\
\hline
\end{tabular}

Kappa coefficients for agreement between 44-hour interdialytic ABPM and casual peridialysis BP: Pre-HD SBP and ASBP $=0.32$. Pre-HD DBP and ADBP $=0.43$. Post-HD SBP and ASBP $=0.42$. Post-HD DBP and ADBP $=0.60$.

$\mathrm{HD}=$ Hemodialysis; $\mathrm{SBP}=$ systolic blood pressure; $\mathrm{DBP}=$ diastolic blood pressure; ASBP, ADBP = ambulatory SBP or DBP 44-hour average. diabetes in $10(14 \%)$, chronic glomerulonephritis in 7 $(10 \%)$, other causes in $4(6 \%)$ and unknown in 6 patients $(8 \%)$. Coronary artery disease was clinically manifest in 4 $(6 \%)$ patients, congestive heart failure in $3(4 \%)$, cerebrovascular disease in $3(4 \%)$, peripheral vascular disease in 2 (3\%) and autonomic neuropathy in $5(7 \%)$. Twenty (28\%) patients were active smokers.
Mean duration of each hemodialysis session was 239 $\pm 4 \mathrm{~min}$. The mean ultrafiltration (UF), UF/prehemodialysis weight ratio, interdialytic weight gain, and IDWG/ estimated dry weight ratio were $2.54 \pm 1.24 \mathrm{~kg}, 3.64 \pm$ $1.8 \%, 2.30 \pm 1.02 \mathrm{~kg}$, and $3.62 \pm 1.63 \%$, respectively.

Prehemodialysis BP averaged 151/83 $\pm 28 / 15 \mathrm{~mm} \mathrm{Hg}$, while posthemodialysis BP averaged 143/81 $\pm 26 / 15 \mathrm{~mm}$ $\mathrm{Hg}$. Average interdialytic BP was 136/83 $\pm 22 / 14 \mathrm{~mm} \mathrm{Hg}$. 
Forty-four patients (71\%) were taking antihypertensive medications (mean $1.7 \pm 1.0$ drugs; range 1-4 drugs). Drugs employed belonged to all different classes. Due to limited numbers in each class, we will not present separate analyses of ABPM data according to type of antihypertensive drug used.

A summary of the ABPM data is shown in table 1 . Most notable were the findings of a significant increase in SBP, DBP and PP in the second interdialytic day when compared to day 1 . This applied to both awake and sleep readings. Figure 1 provides a pictorial description of this pattern of progressive rise in BP levels. The diurnal variation of blood pressure was partly preserved, though night/ day BP ratios were low (table 1) and the number of patients in the non-dipper arbitrary category was very high (51 to $83 \%)$ according to which BP category or interdialytic day was used for categorization). A trend toward less dipping of both SBP and DBP was noted as the interdialytic period progressed, though this was not statistically significant.

The correlations between 48-hour blood pressure parameters and IDWG $(r=-0.07$ for systolic BP and $r=$ -0.09 for diastolic BP) and IDWG/EDW ( $r=0.12$ for systolic $\mathrm{BP}$ and $\mathrm{r}=0.13$ for diastolic BP) were not significant. Likewise, no statistically significant correlation was established between BP parameters and kt/V urea, hematocrit, and EPO dose.

We established the prevalence of uncontrolled HTN in our cohort by pre-HD, post-HD and interdialytic ambulatory BP values using commonly used definitions (BP $\geq 140 / 90 \mathrm{~mm} \mathrm{Hg}$ for casual values, and $\geq 135 / 85 \mathrm{~mm} \mathrm{Hg}$ for ambulatory values). Using such definitions, the prevalence of uncontrolled systolic BP was 66\% (47/71), 58\% $(41 / 71)$ and $45 \%(32 / 71)$ using pre-HD, post-HD and interdialytic SBP, respectively. The prevalence of uncontrolled diastolic BP was 35\% (25/71), 32\% (23/71) and $39 \%(28 / 71)$. In these patients, BP was poorly controlled regardless of presumed adequate dry weight and prescribed antihypertensive drugs. Interestingly, many of the patients who fulfilled the definition of uncontrolled HTN on casual measurements had normal ambulatory parameters (table 2). Overall, the agreement between casual and ambulatory BP values, as assessed by the kappa coefficient, was no better than fair $(0.21-0.4)$ to moderate (0.41-0.6) (table 2, footnotes).

Using ambulatory systolic BP as the most relevant item for classification, we noted that the vast majority of uncontrolled patients were so despite being on antihypertensive drugs $(90 \%, 29 / 32)$. Patients whose SBP was controlled, on the other hand, represented a mixture of
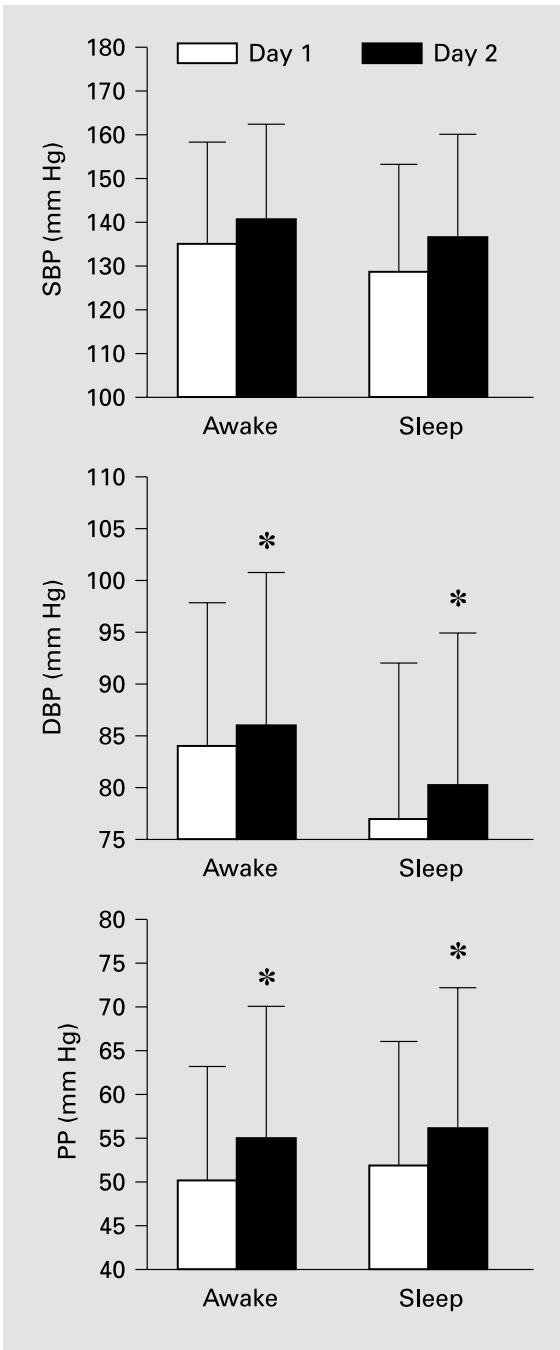

Fig. 1. Ambulatory blood pressure values on each interdialytic day. SBP = Systolic BP; $\mathrm{DBP}=$ diastolic $\mathrm{BP} ; \mathrm{PP}=$ pulse pressure. $* \mathrm{p}<0.05$.

patients managed with $(33 \%, 15 / 39)$ or without $(62 \%, 24 /$ 39) need for antihypertensive agents. Table 3 provides further comparisons between the groups with controlled and uncontrolled BP (for this analysis we combined patients with high SBP or DBP, which resulted in 36 patients with controlled and 35 with uncontrolled BP). It is also noticeable that the pattern of progressive rise of $\mathrm{BP}$ during the interdialytic period occurred in both groups independently of BP control. Night:day diastolic BP ratio was significantly higher in the group with uncontrolled BP on the first interdialytic day, but not on the second interdialytic day. The number of non-dippers for diastolic blood pressure was significantly higher in the first inter- 
Table 3. Demographic, clinical and ABPM data from hemodialysis patients with controlled 44-hour ABPM $<135 / 85 \mathrm{~mm} \mathrm{Hg}$ and uncontrolled 44-hour ABPM $\geq 135 / 85 \mathrm{~mm} \mathrm{Hg}$ blood pressure $($ mean $\pm \mathrm{SD})$

\begin{tabular}{|c|c|c|c|}
\hline & $\begin{array}{l}\text { Controlled BP } \\
\mathrm{n}=36\end{array}$ & $\begin{array}{l}\text { Uncontrolled } \\
\mathrm{n}=35\end{array}$ & $\mathrm{p}$ \\
\hline Age & $45.6 \pm 14.0$ & $45.3 \pm 13.9$ & 0.915 \\
\hline Gender M/F, \% & $19 / 17(53 / 47)$ & $17 / 18(49 / 51)$ & 0.723 \\
\hline Race W/B, \% & $18 / 18(50 / 50)$ & $17 / 18(49 / 51)$ & 0.904 \\
\hline Months on dialysis & $17(4-108)$ & $24(3-153)$ & 0.596 \\
\hline Dialysis session, min & $239.2 \pm 5$ & $240 \pm 0$ & 0.328 \\
\hline Vasoactive drugs & $0.6 \pm 0.9$ & $1.5 \pm 0.9$ & $<0.001$ \\
\hline $\mathrm{Kt} / \mathrm{V}$ urea & $1.33 \pm 0.32$ & $1.31 \pm 0.30$ & 0.802 \\
\hline Hematocrit & $29.5 \pm 5.8$ & $29.1 \pm 3.6$ & 0.677 \\
\hline EPO dose, units/week & $5,550.00 \pm 3667$ & $7,028.57 \pm 4154.98$ & 0.116 \\
\hline $\mathrm{UF}, \mathrm{kg}$ & $2.88 \pm 1.28$ & $2.2 \pm 1.23$ & 0.02 \\
\hline UF\% & $3.70 \pm 1.55$ & $3.57 \pm 2.05$ & 0.751 \\
\hline IDWG, kg & $2.53 \pm 1.01$ & $2.06 \pm 0.99$ & 0.053 \\
\hline IDWG\% & $3.70 \pm 1.34$ & $3.53 \pm 1.89$ & 0.657 \\
\hline Pre BP, mm Hg & $138 \pm 23 / 77 \pm 16$ & $163 \pm 23 / 89 \pm 16$ & $<0.001 /<0.001$ \\
\hline Post BP, mm Hg & $130 \pm 21 / 72 \pm 13$ & $157 \pm 24 / 89 \pm 13$ & $<0.001 /<0.001$ \\
\hline 44 h BP mm Hg & $118 \pm 12 / 73 \pm 12$ & $153 \pm 15 / 93 \pm 12$ & $<0.001 /<0.001$ \\
\hline $44 \mathrm{~h} \mathrm{PP}, \mathrm{mm} \mathrm{Hg}$ & $44 \pm 8$ & $60 \pm 13$ & $<0.001$ \\
\hline Awake BP day $1, \mathrm{~mm} \mathrm{Hg}$ & $117 \pm 13 / 75 \pm 9$ & $153 \pm 14 / 94 \pm 12$ & $<0.001 /<0.001$ \\
\hline Awake PP day $1, \mathrm{~mm} \mathrm{Hg}$ & $42 \pm 7$ & $59 \pm 12$ & $<0.001$ \\
\hline Sleep BP day $1, \mathrm{~mm} \mathrm{Hg}$ & $110 \pm 14 / 67 \pm 8$ & $148 \pm 16 / 88 \pm 13$ & $<0.001 /<0.001$ \\
\hline Sleep PP day $1, \mathrm{~mm} \mathrm{Hg}$ & $44 \pm 10$ & $60 \pm 13$ & $<0.001$ \\
\hline Awake BP day $2, \mathrm{~mm} \mathrm{Hg}$ & $124 \pm 13 / 76 \pm 13$ & $156 \pm 17 / 95 \pm 13$ & $<0.001 /<0.001$ \\
\hline Awake PP day $2, \mathrm{~mm} \mathrm{Hg}$ & $47 \pm 9$ & $61 \pm 14$ & $<0.001$ \\
\hline Sleep BP day $2, \mathrm{~mm} \mathrm{Hg}$ & $119 \pm 14 / 70 \pm 12$ & $153 \pm 19 / 90 \pm 12$ & $<0.001 /<0.001$ \\
\hline Sleep PP day $2, \mathrm{~mm} \mathrm{Hg}$ & $48 \pm 10$ & $64 \pm 17$ & $<0.001$ \\
\hline Night/day SBP ratio day 1 & $0.93 \pm 0.13$ & $0.97 \pm 0.07$ & 0.158 \\
\hline Night/day DBP ratio day 1 & $0.89 \pm 0.09$ & $0.94 \pm 0.08$ & 0.010 \\
\hline Night/day SBP ratio day 2 & $0.96 \pm 0.08$ & $0.98 \pm 0.08$ & 0.342 \\
\hline Night/day DBP ratio day 2 & $0.92 \pm 0.10$ & $0.94 \pm 0.08$ & 0.278 \\
\hline Dip/non-dip SBP day 1 & $10 / 26$ & $6 / 29$ & 0.091 \\
\hline Dip/non-dip DBP day 1 & $24 / 12$ & $11 / 24$ & 0.002 \\
\hline Dip/non-dip SBP day 2 & $7 / 29$ & $5 / 30$ & 0.562 \\
\hline Dip/non-dip DBP day 2 & $18 / 18$ & $11 / 24$ & 0.111 \\
\hline
\end{tabular}

$\mathrm{W}=$ White; $\mathrm{B}=$ black; HD = hemodialysis; UF = ultrafiltration; UF $\%=$ ultrafiltration/ pre-dialysis weight; IDWG = interdialytic weight gain; IDWG $\%=$ IDWG/estimated dry weight; $\mathrm{SBP}=$ systolic blood pressure; $\mathrm{DBP}=$ diastolic blood pressure; $\mathrm{PP}=$ pulse pressure; Dip = dipper nocturnal BP fall $\geq 10 \%$; non-dip = non-dipper nocturnal BP fall $<10 \%$; day $1=$ 1 st interdialytic day, day $2=2$ nd interdialytic day. dialytic day. These data indicate that the group with wellcontrolled BP had a quantitatively greater decline of BP during sleep, but the average fall on either interdialytic day still fell within the arbitrary range on non-dipping.

The analysis of dipping characteristics has to be performed with caution, since there are data to suggest poor long-term reproducibility of dipping in hemodialysis patients [3]. Accordingly, we chose to analyze the clinical characteristics of dippers and non-dippers based on patients who fell on the same category for both interdialytic days, taken as evidence of at least short-term concor- dance. In order to make the analysis possible, we used the nocturnal fall of systolic BP as the index variable to classify patients as dippers or non-dippers. Using this criterion, 12 subjects (17\%) moved from one category to another between days 1 and 2 and were removed from the analysis. Fifty-one patients $(72 \%)$ were nondippers, and 8 (11\%) had a dipper profile on both interdialytic days. We also determined the frequency of reverse dipping (night:day ratio $>1.0$ ) and extreme dipping (night:day ratio $\leq 0.8$ ) in these patients. Among the 51 non-dippers, 11 had a reversed circadian BP profile on at least one of 
Table 4. Clinical differences between patients with a dipper or a nondipper profile on ambulatory BP monitoring $($ mean $\pm \mathrm{SD})$

\begin{tabular}{lccc}
\hline & $\begin{array}{l}\text { Dippers } \\
(\mathrm{n}=8)\end{array}$ & $\begin{array}{l}\text { Non-dippers } \\
(\mathrm{n}=51)\end{array}$ & $\mathrm{p}$ \\
\hline Age, years & $42 \pm 12$ & $46 \pm 13$ & 0.42 \\
Gender (M/F), \% & $5 / 362 / 38$ & $23 / 2845 / 55$ & 0.36 \\
Months on dialysis & $19(5-84)$ & $12(4-153)$ & 0.83 \\
UF, kg & $2.0 \pm 1.0$ & $2.5 \pm 1.3$ & 0.35 \\
UF\% & $3.0 \pm 1.2$ & $3.5 \pm 1.7$ & 0.42 \\
IDWG, kg & $1.9 \pm 1.0$ & $2.2 \pm 1.0$ & 0.27 \\
IDWG\% & $2.9 \pm 1.4$ & $3.5 \pm 1.4$ & 0.22 \\
Vasoactive drugs (yes/no), \% & $6 / 2(75 / 25)$ & $32 / 19(63 / 37)$ & 0.50 \\
Vasoactive drugs & $1.1 \pm 0.8$ & $1.1 \pm 1.1$ & 0.99 \\
Controlled BP yes/no, \% & $5 / 3(63 / 37)$ & $24 / 27(47 / 53)$ & 0.42 \\
44-hour BP, mm Hg & $129 \pm 20 / 81 \pm 12$ & $137 \pm 21 / 83 \pm 13$ & $0.33 / 0.67$ \\
44-hour PP, mm Hg & $46 \pm 9$ & $53 \pm 14$ & 0.21 \\
\hline
\end{tabular}

Dipper $=$ Nocturnal BP fall $\geq 10 \%$; non-dipper $=$ nocturnal $\mathrm{BP}$ fall $<10 \%$; UF $=$ ultrafiltration; UF\% = ultrafiltration/pre-dialysis weight; IDWG = interdialytic weight gain; IDWG $\%=$ IDWG/estimated dry weight; SBP = systolic blood pressure; DBP = diastolic blood pressure; $\mathrm{PP}=$ pulse pressure. the interdialytic days, and 5 patients were reverse dippers on both days. Among the 8 dippers, three had an extremedipper profile in one of the interdialytic days, but no patient fell into this arbitrary category on both days. Table 4 presents a detailed comparison between dipper and non-dipper subjects. Due to the large differences in size between the groups, most variables showed no statistically significant differences, but some trends could be noted, such as lower interdialytic weight gain, and a lower interdialytic BP in the dipper group. Our study was not adequately powered to assess such differences more appropriately.

We were interested in evaluating the impact of antihypertensive drugs on interdialytic BP. Thus, we separated patients in two groups according to the use of vasoactive drugs (table 5). Forty-four subjects (62\%) were taking antihypertensive medications (mean $1.7 \pm 0.8$ drugs; range 1-3 drugs), and 27 (38\%) were not. Patients on antihypertensive drugs had less interdialytic weight gain and ultrafiltration (though these differences were not significant after adjustments for pre-dialysis weight and estimated dry weight, respectively), and had a higher prevalence of uncontrolled hypertension. In fact, all BP parameters were higher in this group, including pre- and post-hemodialysis BP, and interdialytic BP and pulse pressure.

In order to assess the possible role of time of the day when hemodialysis is performed on BP values and diurnal profile, we analyzed ABPM according to two separate groups: those dialyzed in the morning $(\mathrm{n}=38)$ and those whose dialysis took place in the afternoon shifts $(n=33)$. As summarized in table 6, the only difference achieving statistical significance between the two groups was the size of the nocturnal dip on the second interdialytic day. However, the magnitude of this difference was relatively small, fell within the arbitrary definition of non-dipping, and is of questionable clinical significance. All other clinical variables analyzed in the previous tables were not different between groups (data not shown).

\section{Discussion}

In this study we analyzed the ABPM data of 71 hemodialysis patients in the period between two midweek hemodialysis sessions and we used ABPM to delineate the profile of interdialytic BP and possible factors impacting on this profile as well as on the presence or absence of BP control. This study provides ABPM data in a large group of patients managed in a style that is representative of current western hemodialysis practices from the aspects of age, common etiologies of end-stage renal disease, erythropoietin use, average interdialytic weight gain, duration of HD sessions, and prevalence of poorly controlled HTN. Thus, this study lends itself as a useful database for clinical and research reference.

The predominant pattern of blood pressure behavior observed in our patients was one of progressive increase 
Table 5. Clinical distinction between patients using and those not using antihypertensive drugs (mean $\pm \mathrm{SD}$ )

\begin{tabular}{lccc}
\hline & $\begin{array}{l}\text { No drugs } \\
(\mathrm{n}=27)\end{array}$ & $\begin{array}{l}\text { Drugs } \\
(\mathrm{n}=44)\end{array}$ & $\mathrm{p}$ \\
\hline Age & $46 \pm 16$ & $45 \pm 13$ & 0.87 \\
Gender (M/F), \% & $18 / 967 / 33$ & $18 / 2649 / 51$ & 0.04 \\
Months on dialysis & $16(4-108)$ & $17(4-153)$ & 0.52 \\
Kt/V urea & $1.33 \pm 0.35$ & $1.31 \pm 0.29$ & 0.86 \\
Hematocrit & $29.4 \pm 6.5$ & $29.2 \pm 3.4$ & 0.88 \\
EPO dose, U/week & $5,881 \pm 4060$ & $6,523 \pm 3920$ & 0.51 \\
UF, kg & $3.0 \pm 1.3$ & $2.3 \pm 1.2$ & 0.03 \\
UF\% & $3.8 \pm 1.4$ & $3.5 \pm 2$ & 0.50 \\
IDWG, kg & $2.7 \pm 1.1$ & $2.08 \pm 0.9$ & 0.02 \\
IDWG\% & $3.8 \pm 1.3$ & $3.5 \pm 1.8$ & 0.51 \\
Controlled BP (yes/no), \% & $24 / 389 / 11$ & $12 / 3227 / 73$ & $<0.001$ \\
Pre BP, mm Hg & $140 \pm 25 / 76 \pm 12$ & $157 \pm 29 / 88 \pm 15$ & $0.01 /<0.001$ \\
PostBP, mm Hg & $134 \pm 24 / 71 \pm 13$ & $150 \pm 25 / 86 \pm 13$ & $0.003 /<0.001$ \\
44-hour BP, mm Hg & $122 \pm 19 / 74 \pm 9$ & $144 \pm 20 / 88 \pm 13$ & $<0.001 /<0.001$ \\
44-hour PP, mm Hg & $47 \pm 13$ & $55 \pm 13$ & $<0.001$ \\
Night/day SBP ratio day 1 & $0.95 \pm 0.07$ & $0.95 \pm 0.12$ & 0.75 \\
Night/day DBP ratio day 1 & $0.89 \pm 0.09$ & $0.93 \pm 0.08$ & 0.09 \\
Night/day SBP ratio day 2 & $0.96 \pm 0.06$ & $0.98 \pm 0.09$ & 0.39 \\
Night/day DBP ratio day 2 & $0.92 \pm 0.09$ & $0.94 \pm 0.09$ & 0.26 \\
& & & \\
\hline
\end{tabular}

$\mathrm{UF}=$ Ultrafiltration; UF\% = ultrafiltration/pre-dialysis weight; IDWG = interdialytic weight gain; IDWG $\%=$ IDWG/estimated dry weight; controlled BP = 44-hour ambulatory $\mathrm{BP}<135 / 85 \mathrm{~mm} \mathrm{Hg}$; SBP = systolic blood pressure; DBP = diastolic BP; day 1 = 1st interdialytic day; day $2=2$ nd interdialytic day.
Table 6. Ambulatory BP monitoring data according to hemodialysis shift time of the day

\begin{tabular}{lccl}
\hline & $\begin{array}{l}\text { Morning } \\
(\mathrm{n}=38)\end{array}$ & $\begin{array}{l}\text { Afternoon } \\
(\mathrm{n}=33)\end{array}$ & $\mathrm{p}$ \\
\hline Pre BP, mm Hg & $153 \pm 32 / 84 \pm 17$ & $148 \pm 23 / 83 \pm 13$ & $0.41 / 0.76$ \\
Post BP, mm Hg & $144 \pm 31 / 80 \pm 17$ & $143 \pm 20 / 81 \pm 12$ & $0.96 / 0.66$ \\
44-hour BP, mm Hg & $137 \pm 23 / 83 \pm 14$ & $134 \pm 21 / 82 \pm 14$ & $0.50 / 0.76$ \\
44-hour PP, mm Hg & $53 \pm 15$ & $50 \pm 12$ & 0.35 \\
Night/day SBP ratio day 1 & $0.96 \pm 0.07$ & $0.94 \pm 0.13$ & 0.45 \\
Night/day DBP ratio day 1 & $0.91 \pm 0.09$ & $0.92 \pm 0.09$ & 0.73 \\
Night/day SBP ratio day 2 & $0.99 \pm 0.09$ & $0.95 \pm 0.06$ & $0.035^{*}$ \\
Night/day DBP ratio day 2 & $0.94 \pm 0.10$ & $0.93 \pm 0.08$ & 0.56
\end{tabular}

$\mathrm{SBP}=$ Systolic blood pressure $\mathrm{DBP}=$ diastolic $\mathrm{BP} ; \mathrm{PP}=$ pulse pressure. in BP during the interdialytic period and lack of nocturnal fall of BP. This pattern is the most prevalent in patients on hemodialysis [6-11], though some have observed a steady behavior of BP in the interdialytic period [16-18] and preservation of circadian BP rhythm in selected hemodialysis groups $[16,17]$.

Although there was a significant increase in blood pressure in the second interdialytic day, there was no relation- ship with the concomitant increase in body weight. The same relationship was also not significant when we analyzed the blood pressure for the entire interdialytic period. Similarly, other investigators have failed to demonstrate a relationship between the increase in body weight and the interdialytic blood pressure profile [19-22], even though it is well known that blood pressure management in hemodialysis is dependent on control of extracellular 
volume. One possible explanation in our patients is that many were using vasoactive drugs for hypertension treatment and it could have decreased vascular resistance, thereby minimizing the volume-dependent component of blood pressure. However, in our series, even the patients who were not taking antihypertensive drugs did not have a significant correlation of the interdialytic blood pressure with the IDWG (data not shown). This may reflect individual differences of blood pressure response to the weight gain that may be dependent on various determinants of cardiac performance and vascular resistance [22]. Another possibility to explain this observation was raised by Sorof et al. [23], who studied fluctuations in interdialytic BP in relationship to weight measured four times a day in patients in a clinical research center. In their study, BP tracked changes in weight quite well only when sequential measures were obtained, and the authors postulated that significant correlations could be obtained only when several measures of weight were made in the interdialytic period.

Our data also demonstrated a blunted nocturnal decline of blood pressure in a significant number of patients even when they were normotensive. This has been a consistent finding in studies in hemodialysis and its cause is unclear, and probably multifactorial [6-11]. Possible mechanisms include volume overload [9], autonomic dysfunction [24], decreased physical activity [25, 26], sleepdisordered breathing [27], or abnormalities in several hormonal and neuroendocrine mediators (catecholamines, renin, aldosterone, insulin, atrial natriuretic peptide, asymmetric dimethylarginine, parathormone) [7]. In our database, no particular factors could be uncovered as related to non-dipping, such as interdialytic weight gain (after adjustment for EDW), use of antihypertensive drugs, BP control, hematocrit, EPO dose or kt/V urea. In a different set of patients, our group was unable to find any correlation between PTH levels and the nocturnal BP fall [28]. Additionally, though some have observed that patients with controlled BP have more dipping $[16,17]$, we could not reproduce such findings. Similarly, we were unable to establish a difference in the number of antihypertensive agents used by dippers and non-dippers.

The main clinical relevance of the observed prevalence of non-dipping is that, in essential hypertension, non-dipping patients have an increased risk of cardiovascular disease [29], findings that are now being extended to patients with ESRD. Recently, Covic et al. [5] showed that only hemodialysis patients with a persistent non-dipping status had a worsening of echocardiographic parameters (left ventricular dilatation) over a 12-month period. Likewise,
Amar et al. [4] showed that an elevated 24-hour pulse pressure and an elevated nocturnal systolic BP were independent predictors of cardiovascular mortality in a cohort of 57 hemodialysis patients. These data suggest that nondipping status in HD may have a similar pathophysiological significance as it does in essential hypertension. However, the fact that the prevalence of an altered circadian blood pressure pattern in this population is very high and that hemodialysis patients have many other cardiovascular risk factors demand more longitudinal controlled studies to better understand this observation. Furthermore, our group has reported on the limited medium-term (2month) reproducibility of the nocturnal decline of BP in hemodialysis patients [3]. Such limited reproducibility certainly hampers the enthusiasm related to these observations.

Our findings of a high prevalence of uncontrolled BP in the interdialytic period are in agreement with other authors who have shown that hypertension, based on casual BP readings, is poorly controlled in HD patients [1]. Recently, Canella et al. [30] demonstrated that casual readings lead to an inadequate diagnosis of hypertension and that ABPM was able to identify subgroups of hypertensive patients with an increased left ventricular mass. Similar observations have been made by others, though not equipped with the assessment of target organ damage $[2,21,31,32]$. Although we have not compiled data on morbidity or mortality in our patients, we have defined a subgroup of patients who could have a higher risk for cardiovascular diseases. Patients who were hypertensive in the interdialytic period had not only higher 44-hour blood pressure, but also higher blood pressure in each interdialytic day and night, higher ambulatory pulse pressure, higher night/day blood pressure ratio, and higher frequency of non-dipper status. Moreover, the pattern of blood pressure was similar in pre- and post-hemodialysis clinical readings. Lastly, we were not able to evaluate the role of dialysis duration on the prevalence of BP control because our patients were on a fairly uniform range of dialysis duration (around $4 \mathrm{~h}$ thrice weekly). Recent evidence has suggested that duration of hemodialysis sessions may impact on BP independently of volume removal [33], and this issue certainly warrants further evaluation.

Recent evidence has raised the possibility of differences in mortality in hemodialysis patients according to time of the day when they are dialyzed, suggesting that patients dialyzed in the morning may survive longer than those dialyzed in the afternoon, although no mechanistic explanations are available [34]. We analyzed the possibili- 
ty of BP variability being responsible for part of this difference, and found no such association. Our findings are in agreement with three previous publications $[18,21$, 35]. Chazot et al. [18] studied 91 patients on long, slow hemodialysis in Tassin, France. When comparing patients whose long sessions were held during the day versus at night, no statistically significant differences were found in BP parameters, though the group dialyzed at night had a trend towards a lower interdialytic BP. Unfortunately, this large study does not apply to conventional hemodialysis techniques. Nevertheless, the results obtained by Kooman et al. [21] (21 patients) and Huisman et al. (11 patients) [35] mirrored ours, thus it seems unlikely that differences in circadian BP can explain any observations related to prognosis according to dialysis shift.
Because of these many complex interactions impacting on BP during the interdialytic period, many areas of research should be developed to have direct repercussions on the care of hemodialysis patients, such as the impact of drug therapy on the pattern of BP control [36, 37] and circadian BP profile, and perhaps most importantly, the critical evaluation of whether ABPM can improve the definition of hypertension in ESRD by better prediction of outcomes than casual blood pressure measurement.

In conclusion, we have presented a detailed description of ambulatory blood pressure in patients on hemodialysis, where BP control was suboptimal despite pharmacologic therapy of hypertension. These data serve the purpose of better understanding the relationship between BP control and its determinants in this population, while generating questions for further research.

\section{References}

1 Horl MP, Horl WH: Hemodialysis-associated hypertension: Pathophysiology and therapy. Am J Kidney Dis 2002;39:227-244.

2 Agarwal R: Role of home blood pressure monitoring in hemodialysis patients. Am J Kidney Dis 1999;33:682-687.

3 Peixoto AJ, Santos SF, Mendes RB, Crowley ST, Maldonado R, Orias M, Mansoor GA, White WB: Reproducibility of ambulatory blood pressure monitoring in hemodialysis patients. Am J Kidney Dis 2000;36:983-990.

4 Amar J, Vernier I, Rossignol E, Bongard V, Arnaud C, Conte JJ, Salvador M, Chamontin B: Nocturnal blood pressure and 24-hour pulse pressure are potent indicators of mortality in hemodialysis patients. Kidney Int 2000;57: 2485-2491.

5 Covic A, Goldsmith DJ, Covic M: Reduced blood pressure diurnal variability as a risk factor for progressive left ventricular dilatation in hemodialysis patients. Am J Kidney Dis 2000; 35:617-623

6 Townsend RR, Ford V: Ambulatory blood pressure monitoring: Coming of age in nephrology. J Am Soc Nephrol 1996;7:2279-2287.

7 Peixoto AJ, Sica DA: Ambulatory blood pressure monitoring in end-stage renal disease. Blood Press Monit 1997;2:275-282.

8 Mansoor GA, White WB: Ambulatory blood pressure monitoring is a useful clinical tool in nephrology. Am J Kidney Dis 1997;30:591605.

9 Redon J, Oliver V, Zaragoza MD, Galindo MJ: Ambulatory blood pressure during diseases of the kidney. Blood Press Monit 1999;4:267274.

10 Ritz E, Schwenger V, Zeier M, Rychlik I: Ambulatory blood pressure monitoring: Fancy gadgetry or clinically useful exercise? Nephrol Dial Transplant 2001;16:1550-1554.
11 Schomig M, Schwenger V, Ritz E: Circadian rhythm of blood pressure in renal disease. Curr Hypertens Rep 2000;2:490-494.

12 Perloff D, Grim C, Flack J, Frolich ED, Hill M, McDonald M, Morgenstern BZ: Human blood pressure determination by sphygmomanometry. Circulation 1993;88:2460-2470.

13 O'Brien E, Beevers G, Lip GY: ABC of hypertension. Blood pressure measurement. III. Automated sphygmomanometry: ambulatory blood pressure measurement. BMJ 2001;322: 1110-1114.

14 Peixoto AJ, Gray TA, Crowley ST: Validation of the SpaceLabs 90,207 ambulatory blood pressure device for hemodialysis patients. Blood Press Monit 1999;4:217-221.

15 The Scientific Committee: Consensus statementon non-invasive ambulatory blood pressure monitoring. J Hypertens 1990;8(suppl 6):135-140.

16 van de Borne P, Tielemans C, Collart F, Vanherweghem JL, Degaute JP: Twenty-four-hour blood pressure and heart rate patterns in chronic hemodialysis patients. Am J Kidney Dis 1993;22:419-425.

17 Rodby RA, Vonesh EF, Korbet SM: Blood pressures in hemodialysis and peritoneal dialysis using ambulatory blood pressure monitoring. Am J Kidney Dis 1994;23:401-411.

18 Chazot C, Charra B, Laurent G, Didier C, Vo Van C, Terrat JC, Calemard E, Vanel T, Ruffet $\mathrm{M}$ : Interdialysis blood pressure control by long haemodialysis sessions. Nephrol Dial Transplant 1995; 10:831-837.

19 Luik AJ, Gladziwa U, Kooman JP, van Hooff JP, de Leeuw PW, van Bortel LM, Leunissen $\mathrm{KM}$ : Influence of interdialytic weight gain on blood pressure in hemodialysis patients. Blood Purif 1994;12:259-266.
20 Lins RL, Elseviers M, Rogiers P, Van Hoeyweghen RJ, De Raedt H, Zachee P, Daelemans RA: Importance of volume factors in dialysis related hypertension. Clin Nephrol 1997;48: 29-33.

21 Kooman JP, Gladziwa U, Bocker G, Wijnen JA, Bortel L, Luik AJ, de Leeuw PW, van Hoff JP, Leunissen KM: Blood pressure during the interdialytic period in haemodialysis patients: Estimation of representative blood pressure values. Nephrol Dial Transplant 1992;7:917923.

22 Luik AJ, van Kuijk WH, Spek J, de Heer F, van Bortel LM, Schiffers PM, van Hooff JP, Leunissen KM: Effects of hypervolemia on interdialytic hemodynamics and blood pressure control in hemodialysis patients. Am J Kidney Dis 1997;30:466-474.

23 Sorof JM, Brewer ED, Portman RJ: Ambulatory blood pressure monitoring and interdialytic weight gain in children receiving chronic hemodialysis. Am J Kidney Dis 1999;33:667674.

24 Perin PC, Maule S, Quadri R: Sympathetic nervous system, diabetes, and hypertension. Clin Exp Hypertens 2001;23:45-55.

25 Kurtner NG, Cardenas DD, Bower JD: Rehabilitation, aging and chronic renal disease. Am J Phys Med Rehabil 1992;71:97-101.

26 O’Shea JC, Murphy MB: Nocturnal blood pressure dipping: A consequence of diurnal physical activity blipping? Am J Hypertens 2000;13: 601-606.

27 Zoccali C, Benedetto FA, Tripepi G, Cambareri F, Panuccio V, Candela V, Mallamaci F, Enia G, Labate C, Tassone F: Nocturnal hypoxemia, night-day arterial pressure changes and left ventricular geometry in dialysis patients. Kidney Int 1998;53:1078-1084. 
28 Peixoto AJ, Crowley ST, Mansoor GA, Moranino M, Halley S, White WB: PTH and EPO do not determine the nocturnal decline of BP in hemodialysis patients. J Am Soc Nephrol 1998; 9:328A.

29 Verdecchia P: Prognostic value of ambulatory blood pressure: Current evidence and clinical implications. Hypertension 2000;35:844-851.

30 Cannella G, Paoletti E, Ravera G, Cassottana P, Araghi P, Mulas D, Peloso G, Delfino R, Messa P: Inadequate diagnosis and therapy of arterial hypertension as causes of left ventricular hypertrophy in uremic dialysis patients. Kidney Int 2000;58:260-268.
31 Agarwal R, Lewis RR: Prediction of hypertension in chronic hemodialysis patients. Kidney Int 2001;60:1982-1989.

32 Coomer RW, Schulman G, Breyer JA, Shyr Y: Ambulatory blood pressure monitoring in dialysis patients and estimation of mean interdialytic blood pressure. Am J Kidney Dis 1997;29: 678-684.

33 Luik AJ, vd Sande FM, Weideman P, Cheriex E, Kooman JP, Leunissen KM: The influence of increasing dialysis treatment time and reducing dry weight on blood pressure control in hemodialysis patients: A prospective study. Am J Nephrol 1997;21:471-478.2001
34 Bliwise DL, Kutner NG, Zhang R, Parker KP: Survival by time of day of hemodialysis in an elderly cohort. JAMA 2001;286:2690-2694.

35 Huisman RM, de Bruin C, Klont D, Smit AJ: Relationship between blood pressure during haemodialysis and ambulatory blood pressure in between dialyses. Nephrol Dial Transplant 1995;10:1890-1894.

36 Agarwal R: Supervised atenolol therapy in the management of hemodialysis hypertension. Kidney Int 1999;55:1528-1535.

37 Agarwal R, Lewis R, Davis JL, Becker B: Lisinopril therapy for hemodialysis hypertension: hemodynamic and endocrine responses. Am J Kidney Dis 2001;38:1245-1250. 